\title{
Correction: Patil, A. et al. Hub Promiscuity in Protein-Protein Interaction Networks. Int. J. Mol. Sci. 2010, 11, 1930-1943
}

\author{
Ashwini Patil ${ }^{1}$, Kengo Kinoshita ${ }^{2,3}$ and Haruki Nakamura ${ }^{4, *}$ \\ 1 Human Genome Center, Institute of Medical Science, The University of Tokyo, \\ 4-6-1 Shirokane-dai, Minato-ku, Tokyo 108-8639, Japan; E-Mail: ashwini@hgc.jp \\ 2 Graduate School of Information Sciences, Tohoku University, 6-3-09, Aramaki-aza-aoba, \\ Aoba-ku, Miyagi, 982-0036, Japan; E-Mail: kengo@ecei.tohoku.ac.jp \\ 3 Bioinformatics Research and Development, Japan Science and Technology Corporation, \\ 4-1-8 Honcho, Kawaguchi, Saitama 332-0012, Japan \\ 4 Institute for Protein Research, Osaka University, 3-2 Yamadaoka, Suita, Osaka 565-0871, Japan \\ * Author to whom correspondence should be addressed. E-Mail: harukin@protein.osaka-u.ac.jp; \\ Tel.: +81-6-6879-4311; Fax: +81-6-6879-8636.
}

Received: 23 July 2010 / Published: 27 July 2010

We would like to change reference 56 on page 1942 of the article [1] from:

56. Fromer, M.; Yanover, C.; Linial, M. Design of multispecific protein sequences using probabilistic graphical modeling. Proteins 2009, 78, 530-547.

To the correct one as follows:

56. Fromer, M.; Shifman, J.M. Tradeoff Between Stability and Multispecificity in the Design of Promiscuous Proteins. PLoS Comput. Biol. 2009, 5, e1000627.

We apologize for any inconvenience brought to the readers.

\section{References}

1. Patil, A.; Kinoshita, K.; Nakamura, H. Hub Promiscuity in Protein-Protein Interaction Networks. Int. J. Mol. Sci. 2010, 11, 1930-1943.

(C) 2010 by the authors; licensee MDPI, Basel, Switzerland. This article is an Open Access article distributed under the terms and conditions of the Creative Commons Attribution license (http://creativecommons.org/licenses/by/3.0/). 